\title{
Ethics: Application in the Health of the Cuban Population
}

\author{
Verdecia Tamayo MJ'1* and Gómez Lima LA² \\ ${ }^{1}$ Doctor in political science from the University of Havana, Professor at the University of \\ Granma, Cuba \\ ${ }^{2}$ Degree in Education, specializes in History and Philosophy from the "José Marti" Higher \\ Pedagogical Institute of Camaguey, Professor at the University of Granma, Cuba
}

\section{Mini Review \\ Volume 4 Issue 4}

Received Date: October 05, 2021

Published Date: October 21, 2021

DOI: $10.23880 /$ abca-16000204

*Corresponding author: Manuel de Jesús Verdecia Tamayo, Department of Social Science \& political Science, Granma University, Cuba, Tel: 53023572497; Email: mverdeciat@udg.co.cu

\section{Abstract}

The article shows the presence of the ethical foundation in the health actions of the population in Cuba; an essential issue to achieve a diverse and comprehensive perspective of this problem at a global level by publicizing a particular approach to health. For this, the postulates that support the application of ethics in the health development of this population are revealed. Finally, the presence of ethical content in the health treatment of the population in this Caribbean nation is made visible. To carry out the study, a documentary review of press articles, reports from international and national organizations, academic literature and qualitative research is applied. It is concluded that through the ethical content of health actions in Cuba, it has been possible to establish an effective health system that guarantees this right for all citizens because the benefit of specific people with justice and equity for all people is prioritized.

Keywords: Ethics; Cuban Health System; Justice and Equity in Access to Health Services; Applied Ethics

\section{Introduction}

In order to understand how a robust health system has been established in Cuba throughout the evolution of the Cuban Revolution, in the face of dissimilar problems of deep depth, it is necessary to explore the factors that have made it possible to apply an ethical perspective in the health treatment of the a population that has persistently been projected successfully in the short, medium and long term and that has progressively satisfied the needs of the people.

Within the systemic and comprehensive set that makes up the work of the Revolution, public health is identified as one of its main exponents. However, in this recognition, many times it is not taken into account that this result obeys the ethical nature, which favors justice and equity in the right to health of all people. The projection of ethics in society, and especially in the assurance of rights for everyone, is achieved in the revolutionary tradition developed in Cuba, from the nineteenth century to the present day; where progress is made in a culture that takes reality into account and promotes transformative action in favor of justice [1].

From the exercise of power, through a humanistic policy, access to the health system is guaranteed to all people. The purpose of this work is to show the presence of the ethical foundation in the health actions of the population in Cuba; where multiple links, actors, contexts and, especially, the decisions that are made from politics for the development of social justice and a society of law, oriented to the wellbeing of the human being, reach visibility. According to the purposes of the text, it begins by revealing the postulates that support the application of ethics in the health development of this population. Next, the application of the ethical content in the health treatment of the population in this Caribbean nation is made visible. 


\section{Ethical Foundation of the Health Development of the Population in Cuba}

In Cuban revolutionary traditions, with varied nuances, under the economic and social needs of a nation in formation, an organic link is formed between ethics and society, that is, its social application, especially for the solution of the main problems of the population from the establishment of a just social order. From the Christian ethic, men such as Bishop Espada, José Agustín Caballero, Félix Varela and José de la Luz y Caballero, among others, set in the forging seal of the Cuban nation a political and social culture that Western culture assumes based on the interests of the working and exploited population "not only of the country, but of the world" Hart A, et al. [1].

From early on, in the revolutionary tradition, the unity between the scope of national independence, through political sovereignty, with the achievement of social justice in a historical, concrete entity is pointed out: the Cuban nation in its future. For this reason, Varela early, in 1824, stated: "I think that the revolution, or rather: the political change of the Island of Cuba is inevitable. Under this assumption, in order to obtain all the possible advantages and lessen the evils, it must be anticipated and done by the inhabitants themselves, silencing for a moment the voice of the passions, hearing only that of reason and submitting all to the imperious law of necessity" [2].

The revolution is identified first of all with a transcendental political change: the constitution of a free and independent nation, as a transforming means, to act in the resolution of problems, by the inhabitants themselves. The Cuban revolutionaries recognize the achievement of the freedom of the homeland, of popular sovereignty as a necessity to achieve freedom, equality and respect for the inalienable rights of truly existing people; A core issue that already in 1868, the Father of the Nation, De Céspedes, identified as: "the basis of the independence and greatness of the peoples" [3].

The starting point of Fidel Castro, like the rest of the Cuban revolutionaries, was the assumption of certain ethical principles, among them: justice, dignity and the well-being of specific people. These ethical principles were first transmitted to him in his family nucleus; Later they were stimulated and strengthened by the Jesuit teachers, especially the Spanish Jesuit, during their school life, for this reason he recognizes that: "There is no doubt that the Jesuits influenced... in certain elements of one's formation , and in a sense also of justice, perhaps quite elementary, but which meant a starting point (...) an abuse, an injustice, the simple humiliation of another man comes to seem inconceivable in this way (...) then life made it impossible for me to acquire a class culture, a consciousness of a different class and superior to the other. I think that was the basis with which afterwards I already... developed a political conscience" [4].

Fidel Castro from high school became a Martiano. Jose Marti synthesizes the most profound political thought within the nineteenth-century revolutionary tradition. Before the assault on the Moncada, Fidel creatively appropriated Marxism and Leninism in their articulation with national revolutionary traditions [4-6]. This apprehension allowed him to know the methodology and the theoretical foundation for the analysis of the causes, essences, tendencies and solutions of the dissimilar problems of Cuba in the fifties of the 20th century. That is why in La historia me absolverá, Castro, by identifying the six main problems, including the health of the people, establishes links between economic, social and political problems. For this reason, the solution of the population health problem, like the rest of the problems to be solved, is conceived linked "with the conquest of public liberties and political democracy" [7].

Fidel Castro finds in the Cuban revolutionary tradition, especially in Martí, points of contact with Marxism and Leninism referring to the fact that the revolution itself cannot be reduced to the historical fact of the seizure of political power by the revolutionary forces, which it is only a necessary means to initiate social, political, economic and cultural transformation for the benefit of the people. The revolutionary struggle of Fidel Castro assumes the people as object-subject of the revolution, which he visualizes early with a plural nature, given its massive condition, as follows: "the great unredeemed mass, whom everyone offers and whom everyone deceives and betrays, the one that yearns for a better and more dignified and just country; the one that is moved by ancestral yearnings for justice for having suffered injustice and mockery generation after generation, the one that yearns for great and wise transformations in all orders" [7].

In Fidel Castro, in an ascending way, a style of thinking about politics is formed, whose epistemological and methodological structure presents a new vision of political relations, in which the people are conceived as the protagonist and main beneficiary, power is a means and not an end in itself. That is why he points out: "We do not see politics as ordinary politicians see it. We do not care about personal benefits but rather the benefits of the people (...) if we want power; it is as a means and not as an end in itself" [8].

Fidel acquires an integral perspective of social functioning, where the Cuban Revolution when it triumphs assumes a substantive role, as a transforming instrument, in search of the multilateral development of the people. This 
matter is clarified in the following passage: "politics, that is, the Revolution, is the instrument of education, culture, sports, human values, spiritual values (...) Because the Revolution is made for that, simply by man, for the good of man -that is his objective- and everything that in one way or another can contribute to the well-being and happiness of man in the spiritual order, in the moral order, in the material order, in the social order, that is, in all orders" [9]. The historical circumstances in which Fidel Castro developed the revolutionary struggle, allow him to reveal as a strategic objective: to achieve all possible justice, the Revolution had to assume equity as defining features, which is why health had to be for everyone.

In the following pages, the application of ethical content in the health treatment of the Cuban population is made visible; issue linked to the main formulations about the interrelationships that achieve social justice, as an ethical foundation that guides the transformations that take place in society to guarantee the health of the population, as a constitutive part of the work of the Cuban Revolution, this section it is vital to achieve the purpose of this paper.

\section{Ethical Content in the Health Treatment of the Cuban Population}

Both the ethics and the health of the population constitute characteristics that delineate the work of the Cuban Revolution, a universal synthesis that defines it from the vision of Fidel Castro as fighting "for our dreams of justice for Cuba and for the world, which is the basis of our patriotism, our socialism and our internationalism" [10].

In this conception, strategic and tactical responses are integrated in the short, medium and long term that contain decisions and actions of infrastructure, functional, human resources, the living conditions of the populations, legal, scientific, technical and technology that impact the scope and the purposes of social medicine, public health, sanitary action, epidemiological and social support, the biopharmaceutical industry, chemistry, electro medicine, informatics, mathematics, physics. That is, the health system that should be implemented in the country within its low profile of economic development but with a functioning social system oriented to human dignity, under a premise of José Marti: "With everyone and for the good of all”.

As part of the modern conception of the Cuban leader, in the solution of the population's health problem, from the revolutionary politics the transition from a therapeutic medicine to a preventive one is proposed, for that reason it indicates: "And thus, the Revolution attacks again against diseases and is preparing to save thousands of lives (...) How? By preventing these types of diseases through vaccination.
And so we will fight disease by disease, thus we will reduce the number of epidemics, the number of deaths, the number of victims, and this great purpose will be fulfilled: to go from therapeutic to preventive medicine, that is, to prevent citizens from getting sick" [11].

Barely three years after the revolutionary triumph, Fidel Castro is able to indicate the need to link the coping with illnesses with the formation, training and improvement of the human capital that the moment demands; a matter that is made visible in the next passage: "And the future of our people must be bright, the health of our people bright, when, on the one hand, we fight diseases, we reduce their victims, we fight against them until they disappear; and, on the other hand, contingents of enthusiastic young people, who are hopes of the country, forgers of the health of our people, saviors of lives, enter an institution like this one" [11].

From Fidel Castro's perspective, broad sovereignty should be obtained in the available resources that ensure the health of the population; hence his interest and will to develop national biotechnology; objective to which he concentrated his actions from the eighties. But Fidel, through the political leadership of the Cuban biotechnology industry, indicates the need for the country to guide science and technology in its social and international commitment, which starts from the humanist training of professionals and their contribution to the solution of the social, economic and cultural problems that ensure levels of development necessary to satisfy the basic needs of the entire population.

Aspect that is assumed as a component of continuity of revolutionary politics. For this reason, Díaz-Canel et al. stated that: "what explains the development of Cuban biotechnology and its contribution to the health system is not limited to the fact that we have good institutions and excellent professionals. The historical policy of the Revolution aimed at strengthening the public, free and quality health system, and the political leadership of that industry, particularly the leadership of Fidel, have been decisive (...) The best of Cuban politics in Science and technology have been the social values that have guided it, in particular the interest in putting knowledge at the service of the demands of development and the satisfaction of the basic human needs of the entire population" [12].

In Cuba, health is one of the fundamental rights of the people, whose main guarantor is the State, which must articulate the necessary resources, mobilize and enable the participation of the various population sectors and institutions and organizations in general to achieve access to all population to health services. Approached in this way, the population's health problem takes on a political and ethical character but is also linked to development; while it 
is necessary to overcome inequality, exclusion, poverty and helplessness; which states as follows "As long as health is not considered as a fundamental right of man and a duty of the community, as long as the responsibility of the State and society in health care and care is not recognized, in As long as inequalities in the distribution of health resources do not disappear at the national and international levels, as long as poverty, hunger, ignorance and unhealthiness are not fought head-on, little will be possible to achieve in the improvement of health. Human health in the underdeveloped world" Castro F, et al. [13].

But the exercise of power guided by ethical foundations, based on popular interests and demands, systematically imposes the assumption of new goals and progressive tasks, given the strategic scope of the Revolution. That is why expenses and investments must grow, an issue that is linked to a certain budgetary assurance. This must be accompanied by the will to execute the necessary creative contributions. In the Cuban case, much of the innovative initiative can be seen in the institution of the Family Doctor. This novel program allows taking care of the health of the population they serve, which ranges between 140 and 180 families, without exceeding 1,500 habitants [14].

Democracy, for Fidel Castro, cannot exist in the abstract but has to materialize from the assurance of the rights of all people. The Cuban revolutionary makes an analysis of the correlations between the images and representations of democracy and its realization in the social system, the actions to achieve it from the political sphere and the consequence to achieve it from the dynamics of the political system. The social system in Cuba surpasses the broad acceptance of democracy as a general idea in normative terms; it denies this assumption when it goes to the evaluative plane of its materialization.

In this way, the Cuban people and their leaders carry out a critical evaluation of the functioning of democracy in a given nation, from which the essential elements for the functioning of a democracy are inferred, which is inconceivable without medical assistance; That is why Fidel Castro maintains: "It cannot be democratic, nor can a country where social differences exist, inequality exists, social injustice exists; where millions of people are unemployed, millions of people are without medical assistance, millions of people are without education (...) Under these conditions there cannot be any kind of democracy; well, there is no participation of the people, there is no cooperation among the people" [15].

Even in a context of shortages and economic crisis, as the most critical stage of the Special Period, and the rise of the neoliberal paradigm, the Cuban social system continued its insistence on the question of health of the population as a state responsibility, given the social character which gives it and the function of protecting people that the socialist state has to fulfill permanently; as it exists, according to Castro "to help man, to protect man and to protect man in any circumstance" [16].

Despite the economic, financial and technological limitations, during this period, Castro guides and stimulates the people in the will to fulfill the objectives set, deepens the principle of popular unity based on the interdependence of the components in sharing basic services equally, health available; the successes obtained benefit all people. For this reason, he maintains: "Everywhere we have to make the maximum effort, working on each front. In terms of public health, each child we save is a victory for our revolutionary people; every hundredth of a point that we reduce infant mortality is a victory for our revolutionary people" [17].

Another element that makes up the ethical-health dynamic of the population, in Castro, is the criticism of capitalism and its neoliberal paradigm that advocates the withdrawal of the State as an instrument of social regulation and guarantor of the fundamental rights of citizenship, including the of the health. It visualizes the antagonism between the neoliberal mercantile approach and the humanist perspective that reaches health from the revolutionary politics in Cuba.

The Cuban leader predicts the health problem as one of the most critical problems in the coming years, based on the diagnosis he makes given the progressive neglect of this activity by the respective states under neoliberalism that favors the market, profit and excessive consumption.

The previous ideas are inferred from the following fragment: "What are they achieving with neoliberalism in Latin America and in the world? (...) But, what will happen to human health with more and more new diseases... new bacteria, new viruses, rare diseases, old diseases that are reborn? A weapon as effective as antibiotics were, it is becoming increasingly inefficient due to the use and abuse of such diseases, increasingly resistant strains. Tuberculosis itself, almost extinct, is multiplying rapidly everywhere and is mixed with AIDS; some diseases are mixed with others. We fight against all that and we fight successfully, we make vaccines and we protect our children against almost all diseases. We are advancing in the field of health, which I think is going to be one of the most serious problems in the coming years, according to the World Health Organization... because an increasingly difficult situation is being created" [18].

Another substantive element in the ethical-health logic of the population, from the Cuban perspective, is the 
international projection of solidarity not only from the care point of view, but also in the training of human resources from other nations, which has the Latin American School of Medicine as an example and the constitution of the International Contingent of Specialized Doctors in Disaster Situations and Serious Epidemics "Henry Reeve".

The Cuban Revolution has a history accumulated in collaboration and cooperation with other peoples, with other nations, while humanistic and solidarity internationalism is assumed as one of its root ethical principles; Castro clarifies it as follows: "Our concepts about the human condition of other peoples and the duty of brotherhood and solidarity have never been and will never be betrayed. Tens of thousands of Cuban doctors and health professionals scattered around the world are irrefutable testimony of what I affirm. For them there will never be language barriers, sacrifice, dangers or obstacles. We offer to train professionals willing to fight against death. We will show that there is an answer to many of the planet's tragedies. We show that the human being can and should be better. We demonstrate the value of conscience and ethics. We offer lives [19].

In the way of the ethical content of the health treatment of the population in Cuba, it is also necessary to point out that during the 1980s, Ethics Committees already existed in the Caribbean nation; something necessary because the health sciences must bear in mind the ethics of scientific research [20]. Today, these independent entities can be found at different levels, both in a hospital, healthcare center or polyclinics, even when they are in Primary Health Care. They can also function in a centralized manner, when a committee made up of an entity is appointed to evaluate ethical compliance in a multicenter research, beyond the fact that the institutions involved have their own Ethics Committees.

An important milestone is the emergence in 2014 of the National Health Research Ethics Commission. The work teams of this National Commission are made up of workers from the National Center for Clinical Trials Coordination (CENCEC), the Center for State Control of Medicines, Equipment and Medical Devices (CECMED), chairmen of Ethics Committees and professionals with expertise, directed by the Directorate of Science and Technological Innovation of the Ministry of Public Health (MINSAP), and act coordinated by the CENCEC. Both the Ethics Committees, which operate throughout the country, and the National Commission for Health Research Ethics comply, in their procedure, with the three basic principles of research ethics when it comes to a new product: respect for the subject, beneficence and equity.

Given the emergence of COVID-19 in Cuba, as of March 12, 2020, a group of actions were carried out, including: the establishment of the Pedro Kouri Institute of Tropical
Medicine as the centralized institutional Ethics Committee, as the center leader in infectious diseases and faced with the need to use a group of drugs, with other medical indications, as part of the action protocol in the face of the pandemic.

For effective coping with COVID-19 it has been necessary to articulate science and technology with a sense of responsibility towards and for humanity; For this reason, biomedical research actions emerged regulated by national and international guidelines and regulations that are based on legal norms to carry out studies, such as clinical trials with vaccine candidates, with special emphasis on protecting the dignity, rights, safety and well-being of people [21]. Therefore, when the clinical trial with the vaccine candidate Soberana 01 began, in August 2021, a centralized Committee was created in the National Toxicology Center and at the beginning of Phase II of Soberana 02, which included 910 volunteers and two clinical sites; another attached centralized committee was created, made up of nine researchers.

In Cuba, the vaccination campaign against COVID-19 has begun, and it is a campaign because it is about vaccinating as many people as possible, at the right time based on the results of the health intervention that they indicated would produce the least possible damage and with safety margins for the population. There was a certainty that by vaccinating healthy people, the potential harm would be reduced to the least possible number of adverse events, since it was unethical to induce preventive activities that do not have a clear benefit; this respecting the exercise of values such as the freedom to choose responsibly. The Caribbean nation has a robust vaccination scheme with national and free coverage; which has eradicated many infectious diseases [22].

While it is true that health personnel and other exposed and vulnerable sectors were prioritized at the beginning, now the benefits of Cuban vaccines will be received by the entire population. When it comes to vaccinating the pediatric, adolescent and young population, they go to the vaccination centers in the company of their parents or legal guardian to whom, before the administration of the vaccine, the necessary information is offered about it in a language of course, the benefits are highlighted and any unwanted event that may occur is explained. Once injected, all the people are subject to observation, in the vaccination centers, for a period of time not less than one hour to assess the possible damage. The risks and benefits of vaccines are explained in various ways, including the media and social networks, as well as providing the information the population needs to make a well-founded decision. In addition, adults show informed consent to the extent that they accept or not the vaccination actions. In the case of the pediatric, adolescent and young population, informed consent is assumed by the parents or legal guardian. 


\section{Conclusion}

It is concluded that through the ethical content of health actions in Cuba, it has been possible to establish an effective health system that guarantees this right for all citizens because the benefit of specific people with justice and equity for all people is prioritized. In the Cuban revolutionary tradition, the ethical-health bond of the population is configured from certain basic postulates. In Cuba, the interest in solving the social, economic, political and cultural problems suffered by the people originates on the basis of the formation and development of certain ethical principles transmitted by the founding fathers of the Cuban nation. In the case of Fidel Castro, these principles are formed in his family and strengthened by the influence in his training of Jesuit teachers, mainly Spanish, who stimulate the fight for justice.

The ethical principles serve as a starting point, for Fidel Castro, to ascend and acquire a political culture and consciousness that lead him to the revolutionary struggle. Although from the family context he was able to learn about the deep social inequalities and his life experiences lead him to suffer deficiencies, contact with the revolutionary tradition of his nation and with Marxism and Leninism provide him with the social and humanist content of revolutionary politics. Once political power has been seized, political practice continuously materializes popular aspirations to receive stable and quality health services. Revolutionary politics assumes a political will that focuses on the well-being of specific people, certain health programs are carried out for the population, in search of the well-being of all people without exception.

Under current conditions, the global expansion of the Covid-19 pandemic gives renewed validity to the population's health-ethical dynamics from the vision of Fidel Castro and Cuba, thereby confirming its strategic significance. The Cuban leader and his people transformed a society where the health of the population was one of the six fundamental problems to one of the main achievements of the Cuban Revolution; focused on achieving the maximum possible social justice. Meanwhile, for the vast majority of the world's population, achieving health for all people is an unattainable aspiration, given the exclusionary nature of the prevailing social and political systems.

\section{References}

1. Hart A (2003) Science, consciousness and belief. A Marti perspective. Temas 32: 100-109.

2. Varela F (1824) Tranquility of the island of Cuba. The Habanero. Political, scientific and literary role. In: Félix
Varela (2001) Works, Compilation and notes Eduardo Torres-Cuevas, Jorge Ibarra Cuesta and Mercedes García Rodríguez. City of Havana, Contemporary Image Editions 2: 169-177.

3. De Céspedes CM (1868) Minutes of the 'Rosario', agreement of the uprising. In: Carlos Manuel de Céspedes (1974), Editorial of Social Sciences, pp: 106-107.

4. Castro F (1985) Fidel and religion. Conversations with Frei Betto. Havana, Publications Office of the Council of State.

5. Castro F (1973) Speech delivered at the central act in commemoration of the $20^{\text {th }}$ anniversary of the assault on the Moncada barracks, held on July 26. In: Fidel Castro (1978) Speeches Santiago de Cuba. XX and XXV Anniversaries of the Assault on the Moncada Barracks 1973-1978. La Habana, Political Editor, pp: 9-55.

6. Miranda O (2005) Philosophy, science and society in Fidel Castro. La Habana, Editorial Academia.

7. Castro F (1953) History will absolve me. In: Fidel Castro (2005) History will absolve me. Annotated edition. Publications Office of the Council of State, Cuba.

8. Castro F (1955) Manifesto No. 1 of July 26 to the people of Cuba. In: Fidel Castro (2007) Fidel Castro: Selection of documents, interviews and articles (1952-1956). Political Editor, pp: 82-95.

9. Castro F (1971) First Secretary of the Central Committee of the Communist Party of Cuba and Prime Minister of the Revolutionary Government, in the Summary of the Act in Tribute to the Athletes of the Calegation of the Cuban Sports Player, to the Cuban Players Colombia, Held in the Sports City of Havana.

10. Castro F (2000) Speech Given by the President of The Council of State of the Republic of Cuba, Fidel Castro Ruz, at the Open Tribune of Youth, Students and Workers for the International Day of Workers, in the Plaza of the First Revolution.

11. Castro F (1962) First Secretary of the National Direction of Ori and Prime Minister of the Revolutionary Government in the Opening of the Institute of Science Basic and Pre-Clinical "Victoria De Girón” In Marianao.

12. Diaz-Canel M, Nunez J (2020) Government management and Cuban science in the confrontation with COVID-19. Anales de la Academia de Ciencias de Cuba, 10(2).

13. Castro F (1983) The economic and social crisis in the world its repercussions in underdeveloped countries, its bleak prospects and the need to fight if we want 
to survive. Report to the Vll Summit of Non-Aligned Countries. La Habana, Oficina de Publicaciones del Consejo de Estado.

14. González L, Cuesta L, Pérez L, Presno M, Fernández I, et al. (2018) The Family Doctor and Nurse Program: development of the medical care model in Cuba. Revista Panamericana de Salud Pública.

15. Castro F (1992) A grain of corn. Conversations with Tomás Borge. Havana, Publications office of the Council of State.

16. Castro F (1994) First secretary of the central committee of the communist party of cuba and president of the councils of state and ministers, at the official delivery of the building of the center of immularia molecion in ocecion molecion constructor.

17. Castro F (1996) Speech Made by Chief Commander Fidel Castro Ruz, First Secretary of the Central Committee of the Communist Party Of Cuba And President Of The Councils Of State And Ministers, In Central Peru, Jobabo, Las Tunas, On March 31, 1996 Year of the Centenary of the Fall in Combat of Antonio Maceo.
18. Castro F (1996) Speech delivered at the central act for the XLIII anniversary of the assaults on the Moncada and "Carlos Manuel de Cespedes" barracks, held in the "Calixto García Iñiguez" square, Holguin, on July 26.

19. Castro F (2005) President of the Republic of Cuba, in the act of constitution of the International Contingent of Doctors Specialized in Situations of Disaster and Serious Epidemics "Henry Reeve " and national graduation of medical students, in the Sports City, "Year of the Bolivarian Alternative for the Americas".

20. Del Castillo SD, Rodriguez TN (2018) The ethics of scientific research and its inclusion in the health sciences. Acta Médica del Centro 12(2): 213-227.

21. Pinto JB, Gulfo DR (2013) Assent and informed consent in pediatrics: Bioethical and legal aspects in the Colombian context. Revista Colombiana Bioetica 8(1): 144-165.

22. Triana Y, Marxan V (2021) Bioethics aspects on Informed Consent in the Use of Vaccines in Pediatrics. Revista Habanera 20(2). 